\title{
RUMAH PERAN SI PAI \\ (STRATEGI PENCEGAHAN DAN PENANGANAN KEKERASAN TERHADAP ANAK)
}

\author{
Andi Tanaka \\ Univesitas Brawijaya \\ tanaka.andi@yahoo.com
}

\begin{abstract}
Abstrak: Kekerasan terhadap anak merupakan kasus yang perlu mendapat perhatian khusus oleh semua golongan, termasuk pemerintah. Hal ini dikarenakan anak merupakan harapan dan generasi penerus bangsa di masa yang akan datang. Oleh karena itu diperlukan perlindungan secara khusus agar hak-hak anak tetap terjaga. Perlindungan ini diperlukan karena anak merupakan bagian masyarakat yang mempunyai keterbatasan secara fisik maupun mental. Disini penulis mencoba menawarkan solusi alternatif untuk memberikan perlindungan tehadap anak dari tindakan kekerasan dengan menggagas "Rumah Peran SIPAI". Rumah Peran Si-PAI (Rumah Peran Si-Perlindungan Anak Indonesia) merupakan lembaga di bawah Komisi Perlindungan Anak Indonesia (KPAI) yang bergerak di bidang advokasi dan KOMA (Konseling Masyarakat). Dengan adanya konsep Rumah Peran SIPAI diharapkan dapat menjadi solusi alternatif yang dapat mengakomodasi berbagai macam kebutuhan yang diperlukan oleh anak. Sehingga dengan hadirnya Rumah Peran SIPAI dapat mengoptimalkan peran pemerintah, masyarakat, keluarga, dan orang tua di dalam penyelenggaraan perlindungan anak. Dengan perlidungan optimal inilah diharapkan akan lahir generasi-generasi cerdas, kreatif, dan solutif yang akan dapat memajukan dan mensejahterakan kehidupan bangsa dan negara.
\end{abstract}

Kata Kunci: Anak, Kekerasan, Rumah Peran SI-PAI

\section{Pendahuluan}

Indonesia merupakan negara yang memiliki jumlah penduduk terbesar nomor empat sedunia setelah China, India, dan Amerika. Badan Pusat Statistik mencatat jumlah penduduk Indonesia sebesar 237.641.326 jiwa (http://sp2010.bps.go.id/ diakses pada tanggal 10 Juli 2016). Dari jumlah tersebut $34,26 \%$ atau 81.415.918 orang adalah anak usia 0-17 tahun (http://sp2010.bps.go.id/ diakses pada tanggal 10 Juli 2016). Sebagaimana merujuk pada Pasal 1 angka 1 Undang-undang Nomor 23 Tahun 2002 tentang Perlindungan Anak, yang dimaksud anak adalah seorang yang belum berusia 18 tahun termasuk anak yang yang masih dalam kandungan. Sehingga menurut data diatas persentase jumlah anak di Indonesia terbilang cukup besar.

Perlindungan terhadap anak merupakan sebuah hak konstitusional bagi setiap anak Indonesia. Dalam Pasal $28 \mathrm{~B}$ ayat 2 Undangundang Dasar Negara Republik Indonesia Tahun 1945 (UUD NRI Tahun 1945) disebutkan bahwa: "setiap anak berhak atas kelangsungan hidup, tumbuh, dan berkembang serta berhak atas perlindungan dari kekerasan dan diskriminasi." Sehingga Negara wajib menjamin serta melindungi hak anak yang merupakan $\mathrm{Hak}$ Asasi Manusia (HAM).

Sejalan dengan hal itu, sejak lama Pemerintah Indonesia telah berkomitmen untuk memberikan perlindungan terhadap hak-hak anak Indonesia melalui berbagai regulasi. Pada 


\section{4-151 | HARKAT: Media Komunikasi Islam Tentang Gender dan Anak, 12 (2), 2016}

tahun 1990 Negara Indonesia telah meratifikasi Konvensi Hak Anak (KHA) melalui Keputusan Presiden Republik Indonesia Nomor 36 Tahun 1990, tahun 2000 Negara Indonesia telah menandatangani deklarasi millennium yang dikenal dengan tujuan pembangunan millennium (millennium development goals), dan tahun 2001 Indonesia telah menyatakan komitmennya terhadap Deklarasi Dunia yang Layak Bagi Anak (a world fit for children). Serta terakhir pada tanggal 22 Oktober 2002, Indonesia menetapkan Undang-undang No. 23 tahun 2002 tentang Perlindungan Anak yang berorientasi pada hak-hak anak seperti yang tertuang dalam Konvensi Hak-hak Anak.

Namun, sejauh ini belum ada langkah komprehensif yang dapat memberikan perlindungan terhadap anak dari kekerasan. Padahal menurut Pasal 5 ayat (3) UU No. 23 tahun 2002 tentang Perlindungan Anak, anak tergolong kelompok masyarakat yang cukup rentan terhadap tindakan kekerasan. Selain itu UU No. 23 tahun 2002 juga mengamanahkan agar anak dapat diberikan perlakuan dan perlindungan lebih. Salah satu bentuk perlindungan yang diberikan dengan terimplementasinya program yang digagas oleh pemerintah. Dalam hal ini Kementerian Negara Pemberdayaan Perempuan mulai tahun 2005 memperkenalkan istilah Kota Layak Anak (KLA) di seluruh kabupaten/kota di seluruh Indonesia. Kemudian untuk mempercepat proses perwujudan Kabupaten/Kota Layak Anak disusunlah PUHA (Pengarusutamaan Hak Anak - Mainstreaming Children Rights) sebagai strategi untuk mempercepat penyelesaian permasalahan kekerasan anak di Indonesia. Namun semua yang telah dilakukan pemerintah belum dapat mengatasi permasalahan kekerasan di Indonesia. Bahkan selama tahun 2014, Komisi Nasioanal Perlidungan Anak (Komnas PA) menerima sebanyak 2.737 laporan kekerasan terhadap anak-anak (http://news.liputan6.com/read/2154228/komna s-pa-prediksi-pelaku-kekerasan-anak-meningkat18-tahun-2015 diakses pada tanggal 10 Juli 2016). Hal ini menandakan bahwa negara, pemerintah, masyarakat, keluarga, dan orang tua yang berkewajiban dan bertanggungjawab terhadap penyelenggaraan perlindungan anak tidak berfungsi secara maksimal.

Berdasar pada fakta tersebut disini penulis menggagas rumah perlidungan anak (Rumah Peran) SI-PAI (Sistem Informasi Perlindungan Anak Indonesia) yang digunakan sebagai solusi alternatif pencegahan dan penanganan kekerasan terhadap anak. Rumah Peran SI-PAI ini diharapkan akan dapat mengektifkan kinerja pemerintah dalam memberikan perlindungan terhadap anak.

Rumusan masalah pada penelitian ini di antaranya; Bagaimana problematika kekerasan terhadap anak di Indonesia? Bagaimana strategi pencegahan dan penanganan kekerasan terhadap anak melalui konsep Rumah Peran SI-PAI?

Tujuan penelitian ini di antaranya: mengetahui dan menganalisis problematika kekerasan terhadap anak di Indonesia; mengidentifikasi, menemukan, dan menganalisis strategi pencegahan dan penanganan kekerasan terhadap anak melalui konsep Rumah Peran SIPAI.

Gagasan ini diharapkan dapat membawa manfaat dan memperkaya bagi khasanah keilmuan di Indonesia, khususnya dalam kemajuan di bidang hukum untuk menuju penegakan keadilan yang progresif dan menciptakan masyarakat yang tidak hanya kritis tetapi juga solutif.

Bagi masyarakat, penyusunan karya tulis ini dapat bermanfaat untuk memperkaya khazanah pengetahuan dan memberi informasi mengenai anak, permasalahannya, serta solusi yang coba digagas.

Bagi Pemerintah, serta para pemangku kebijakan yang memiliki kaitan dengan 

perlindungan anak, penyusunan karya tulis ini diharapkan mampu menggugah kesadaran akan kompleksitas permasalahan anak dan mempertimbangkan kebijakan yang telah dan akan diambil terkait dengan konsep perlindungan dan pengembangan potensi anak.

Bagi Mahasiswa, penyusunan karya tulis ini dapat menjadi referensi bacaan serta dapat membuka ruang diskusi untuk perbaikan bersama.

\section{Pembahasan}

\section{Kekerasan Terhadap Anak di Indonesia}

Perlindungan terhadap anak merupakan bagian utama peningkatan kualitas mutu hidup manusia (Sentika, 2007). Karena anak merupakan harapan bagi masa depan suatu bangsa. Khusus bagi Indonesia, fokus perlindungan dan upaya untuk meningkatkan potensi anak, dapat mempercepat pencapaian target yang menjadi tujuan bersama di tahun 2015 dalam program Millenium Development Goals (MDGs) dan World Fit For Children (WFFC). Dengan perlindungan yang optimal, diharapkan akan lahir generasi-generasi cerdas, kreatif, dan solutif yang akan dapat memajukan dan mensejahterakan kehidupan bangsa dan negara.

Namun, sayangnya upaya yang telah dilakukan untuk menanggulangi kekerasan anak belum secara optimal berjalan. Sejauh ini masih banyak kasus kekerasan yang terjadi di Indonesia. Data mengenai kasus kekerasan anak di Indonesia bisa dilihat dari Tabel 1 .
Selanjutnya Komnas PA juga mencatat pelanggaran hak anak di Indonesia pada tahun 2010 dengan jumlah 2.534.774 korban pelanggaran hak anak, dimana kasus tersebut dapat diidenifikasi pada Tabel 2.

\section{Strategi Pencegahan dan Penanganan Kekerasan terhadap Anak Melalui Konsep Rumah Peran SI-PAI}

Program pemberdayaan ibu dan anak banyak diselenggarakan di kota-kota besar di Indonesia. Sayangnya, upaya tersebut cenderung bersifat parsial dan tidak terorganisir, sehingga materi pola asuh yang disampaikan berbedabeda. Dewasa ini, menghadapi banyaknya kasus kekerasan terhadap anak yang semakin menggunung dan sewaktu-waktu bisa menjadi bom waktu, pemerintah kini tidak lagi bisa mengandalkan peran dari lembaga-lembaga tertentu saja, namun harus dibentuk sebuah pola perlindungan yang berkelanjutan, efektif dan efisien. Harus juga memperhatikan keterlibatan aktif antara anak dan orang tua, sehingga akan terjalin komunakis batin yang erat sebagi fungsi proteksi dalam diri. Tidak lupa, status legal yuridis juga harus dimiliki oleh lembaga yang nantinya berperan sebagai pengayom perlindungan anak. Sehingga, pertimbangan perlindungan anak dari kekerasan menggunakan rumah perlindungan di bawah naungan KPAI dianggap sebagai sebuah solusi yang tepat. Konsep rumah peran SI-PAI tersebut terlihat pada Bagan 1. 
Tabel 1. Kompilasi Pantauan Pelanggaran Hak Anak Periode 2007-2009

\begin{tabular}{|c|c|c|c|c|}
\hline \multirow{2}{*}{ No } & \multirow{2}{*}{ Deskripsi } & \multicolumn{3}{|c|}{ Jumlah } \\
\hline & & Tahun 2007 & Tahun 2008 & Tahun 2009 \\
\hline I & Bentuk Kekerasan & & & \\
\hline 1 & Fisik & 341 & 436 & 605 \\
\hline 2 & Seksual & 527 & 626 & 705 \\
\hline 3 & Psikis & 642 & 764 & 688 \\
\hline 4 & Aborsi & 4382 & 2567 & - \\
\hline & Jumlah & 5892 & 4393 & 1998 \\
\hline II & Masalah Hak Penduduk dan Kebebasan & & & \\
\hline 1 & Masalah akte kelahiran & - & 271.814 & 56.408 \\
\hline 2 & Persoalan Bunuh Diri & 17 & 30 & 31 \\
\hline 3 & Anak dan Tawuran & 19 & 42 & 1.006 \\
\hline 4 & Penahanan Bayi di Rumah Sakit & - & - & 7 \\
\hline & Jumlah & 36 & 271.886 & 57.452 \\
\hline III & Masalah Lingkungan dan Perlindungan Alternatif & & & \\
\hline 1 & Penculikan & 71 & 38 & 55 \\
\hline 2 & Penelantaran & 83 & 580 & 226 \\
\hline 3 & Anak Korban Perceraian & 108 & 67 & 34 \\
\hline 4 & Anak Korban Pornografi & 27 & 8 & 22 \\
\hline & Jumlah & 289 & 693 & 337 \\
\hline IV & Masalah Kesehatan Dasar dan Kesejahteraan & & & \\
\hline 1 & Demam Berdarah & 2.500 & 1.920 & 1.981 \\
\hline 2 & Diare & 4.906 & 81.292 & 2.345 \\
\hline 3 & Mal Nutrisi & 1.808 .753 & 2.007 .552 & 7.755 \\
\hline 4 & Flu Burung & 93 & 11 & 528.850 \\
\hline 5 & Polio & 23 & 50 & 11 \\
\hline 6 & HIV/AIDS & 14.593 & 1.999 & 199 \\
\hline & Jumlah & 1.830 .826 & 2.092 .824 & 541.141 \\
\hline V & Masalah Anak Putus Sekolah & & & \\
\hline 1 & Putus SD & 4.127 .492 & 5.255 .110 & 2.041 .000 \\
\hline 2 & Putus SMP & 18.292 .332 & 18.556 .611 & 278.826 \\
\hline 3 & Putus SMU/K & 325.393 & 330.993 & - \\
\hline & Jumlah & 22.749 .217 & 24.152.714 & 2.319 .826 \\
\hline VI & Anak yang Membutuhkan Perlindungan Khusus & & & \\
\hline 1 & Anak Berhadapan Dengan Hukum & 2.341 & 621 & 1.258 \\
\hline 2 & Buruh Anak & 2.100 .000 & 1.399 .573 & 33 \\
\hline 3 & Eksploitasi Seksual Komersial Anak & 690.000 & 459 & 436 \\
\hline 4 & Pembantu Rumah Tangga Anak & - & - & 273 \\
\hline 5 & Perdagangan Bayi & - & - & 10 \\
\hline & Jumlah & 2.792 .341 & 1.400 .653 & 2.010 \\
\hline
\end{tabular}

Sumber: http://komnaspa.or.id 
Tabel 2. Database Pelanggaran Hak Anak di Indonesia Tahun 2010

\begin{tabular}{|c|c|c|}
\hline No & Deskripsi & Jumlah \\
\hline $\mathrm{I}$ & Masalah Hak Sipil dan Kemerdekaan & \\
\hline 1 & Akte Kelahiran & 25.987 \\
\hline 2 & Bunuh Diri Anak & 31 \\
\hline 3 & Tawuran Anak dan Remaja & 42 \\
\hline 4 & Partisipasi & - \\
\hline II & $\begin{array}{l}\text { Jumlah } \\
\text { Masalah Lingkungan Keluarga dan pengasuhan } \\
\text { Alternatif }\end{array}$ & 26.060 \\
\hline 1 & Penelantaran & 208 \\
\hline 2 & $\begin{array}{c}\text { Anak Korban Perceraian } \\
\text { Jumlah }\end{array}$ & $\begin{array}{c}92 \\
300\end{array}$ \\
\hline III & Masalah kesehatan dan Kesejahteraan Dasar & \\
\hline 1 & Demam Berdarah & 3.491 \\
\hline 2 & Campak & 55 \\
\hline 3 & Diare & 24.024 \\
\hline 4 & Mal Nutrisi & 701.052 \\
\hline 5 & Flu Burung & 9 \\
\hline 6 & Polio & 4 \\
\hline 7 & HIV/AIDS & 3.122 \\
\hline 8 & $\begin{array}{l}\text { Bayi ditahan di Rumah Sakit } \\
\text { Jumlah }\end{array}$ & $\begin{array}{c}11 \\
731.768\end{array}$ \\
\hline IV & $\begin{array}{l}\text { Masalah Pendidikan, Waktu Luang, dan Kegiatan } \\
\text { Kultural }\end{array}$ & \\
\hline 1 & Anak Putus Sekolah SD & 526.987 \\
\hline 2 & Anak Putus Sekolah SMP & 4.917 \\
\hline \multirow[t]{2}{*}{3} & Anak Putus Sekolah SMU/K & 1.894 \\
\hline & Jumlah & 533.798 \\
\hline $\mathrm{V}$ & Anak yang Membutuhkan Perlindungan Khusus & \\
\hline I & Kekerasan & \\
\hline 1 & Fisik & 646 \\
\hline 2 & Seksual & 926 \\
\hline \multirow[t]{2}{*}{3} & Psikis & 841 \\
\hline & Sub Total I & 2.413 \\
\hline II & Esploitasi & \\
\hline 1 & Buruh/Pekerja Anak & 238.022 \\
\hline 2 & Perdagangan Anak & 412 \\
\hline 3 & Anak Korban Pornografi & 39 \\
\hline 4 & Penculikan Anak & 111 \\
\hline \multirow[t]{2}{*}{5} & Narkotika & 1.000 .000 \\
\hline & Sub Total II & 1.238 .584 \\
\hline \multirow{2}{*}{ III } & Anak Berkonflik Dengan Hukum & 1.851 \\
\hline & Jumlah & 1.242 .848 \\
\hline \multicolumn{2}{|c|}{ TOTAL ANAK KORBAN PELANGGARAN HAK ANAK } & 2.534 .774 \\
\hline
\end{tabular}

Sumber: http://komnaspa.or.id 


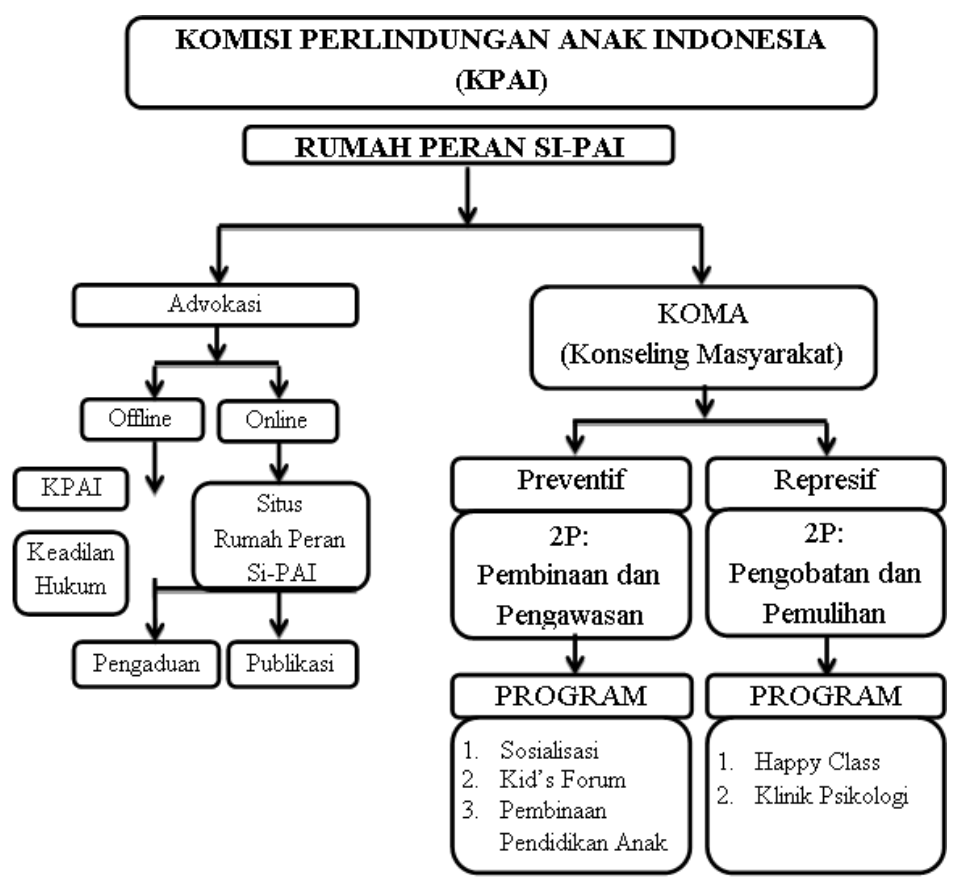

Bagan 1. Konsep Rumah Peran SI-PAI

Keterangan:

Rumah Peran SI-PAI (Rumah Perlindungan Anak Sistem Perlindungan Anak Indonesia) adalah lembaga di bawah Komisi Perlindungan Anak Indonesia (KPAI) yang bergerak dibidang advokasi dan KOMA (Konseling Masyarakat).

\section{Advokasi}

Advokasi merupakan program pendampingan masyarakat.Rumah Peran Si-PAI bergerak di bidang advokasi yakni mendampingi masyarakat agar dapat memperoleh keadilan hukum dalam peradilan dalam penuntasan kasus kekerasan terhadap anak.Advokasi ini di selenggarakan sarana online dan offline.

a. Offline

Program offline merupakan program pengaduan dan pemberitahuan adanya indikasi kekerasan terhadap anak secara langsung ke kantor Rumah Peran Si-PAI. Setelah kasus diterima, kasus akan dipilah-pilah dan diidentifikasi dengan cara penyelidikan secara langsung pada anak, apakah anak terindikasi korban kekerasan atau tidak. Jika anak terindikasi korban kekerasan, maka langkah selanjutnya adalah advokasi si koraban.

\section{b. Online}

Program online merupakan program pengaduan dan pemberitahuan adanya indikasi kekerasan terhadap anak secara tidak langsung melalui situs resmi Rumah Peran Si-PAI. Setelah kasus diterima, kasus akan dipilah-pilah dan diidentifikasi dengan cara penyelidikan secara langsung pada anak, apakah anak terindikasi korban kekerasan atau tidak. Jika anak terindikasi korban kekerasan, maka langkah selanjutnya adalah advokasi si korban.Selain pengaduan dan pemberitahuan tentang kasus kekerasan pada anak, situs ini juga bertujuan untuk publikasi secara secara online. Publikasi yang dimaksud tentang tata cara penyelesaian kasus kekerasan pada anak yang telah ditangani oleh Rumah Peran Si-PAI bersama KPAI.

\section{KOMA}

$$
\text { KOMA (Konseling Masyarakat) }
$$
merupakan program Rumah Peran SI-PAI yang bertujuan untuk peyembuhan emosional dan 
psikologis anak pascakekerasan, serta upaya pencegahan kekerasan pada anak. Program ini disediakan untuk anak yang menghadapi permasalahan kekerasan dan masyarakat yang membutuhkan pembinaan dalam pencegahan kekerasan terhadap anak.Konseling Masyarakat terbagi dalam dua kategori program pelaksanaan, yakni dengan preventif dan represif.

a. Preventif

Upaya Preventif merupakan upaya pencegahan tindakan kekerasan terhadap anak. Upaya ini dilakukan dengan cara pembinaan dan pengawasan yang diterapkan melalui program sosialisasi, pengadaan Kid's Forum dan pembinaan pendidikan anak.

\section{1) Sosialisasi}

Sosialisasi bertujuan untuk memberi informasi dan ilmu kepada masyarakat mengenai berbagai hal yang berhubungan dengan kekerasan pada anak. Misalnya

a) Sosialisasi Pentingnya Pendidikan di Keluarga

b) Sosialisasi Pemidanaan pada Pelaku Kekerasan Terhadap Anak.

Bagan 2. Pihak-pihak yang Terlibat dalam Pelaksaanaan Program Rumah Peran SI-PAI sumber: Konsep Penulis

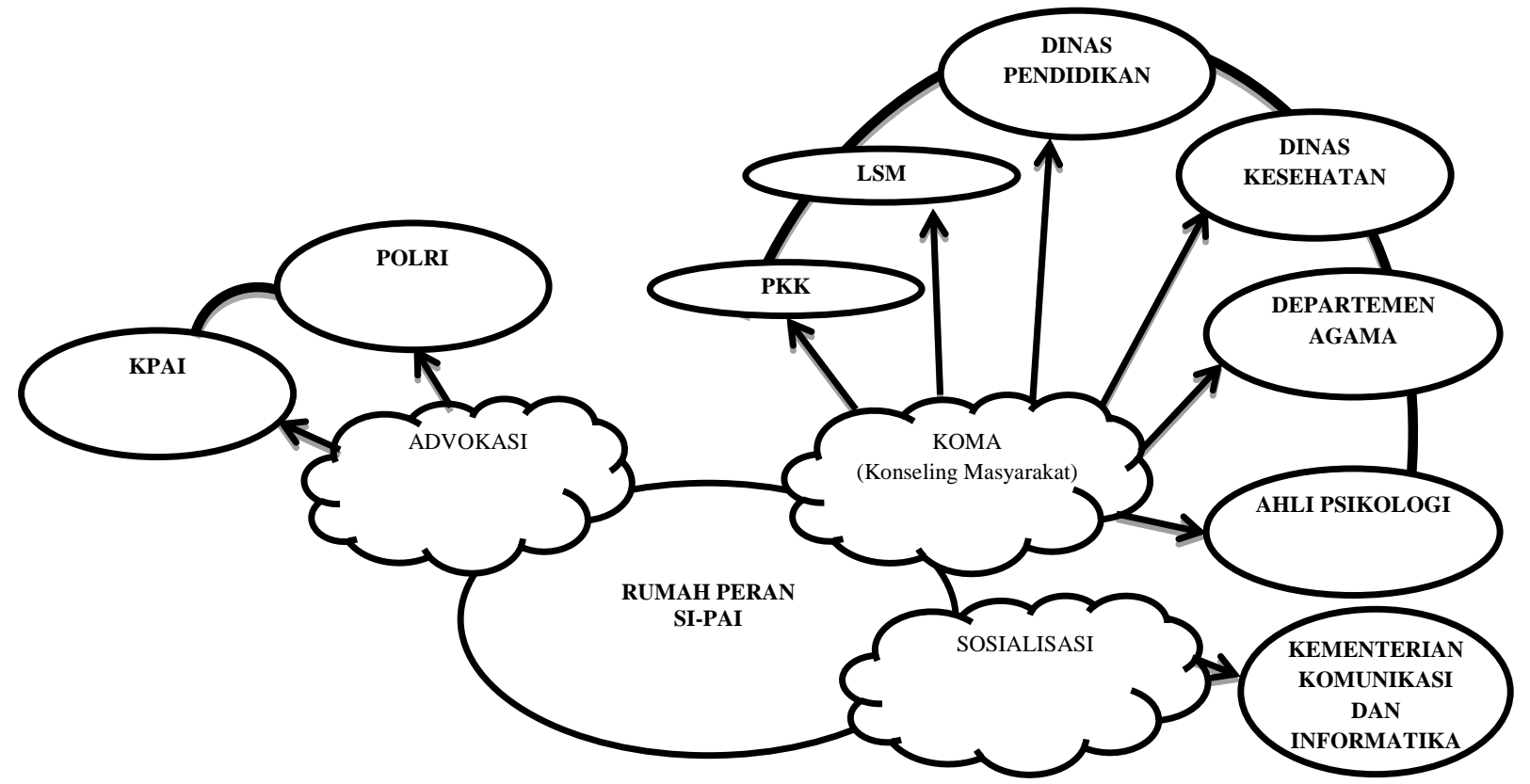

Copyright (C) 2016 | HARKAT | ISSN 1412-2324
2) Kid's Forum

Kid's Forum merupakan program yang melibatkan anak secara langsung dalam kegiatan kajian tentang perlindungan anak dalam perspektif hak-hak anak. Dengan cara memfasilitasi pengembangan pendekatan anak ke anak dalam pencegahan, perlindungan, pemulihan serta reintegrasi korban melalui kelompok atau forum ini.

a) Sanggar Seni Gambar Anak

3) Pembinaan Pendidikan Anak

Pembinaan pendidikan anak dilakukan dengan cara mengadakan seminar/workshop tentang pencegahan dan perlindungan anak.Pembinaan pendidikan anak ini ditujukan untuk masyarakat secara umum, terutama masyarakat yang telah memiliki anak. Contoh dari program ini antara lain:

a) Workshop "Cara Mendidik Anak"

b) Seminar "Memahami Anak dengan Kasih Sayang” b) Forum Bermain 


\section{0-151 | HARKAT: Media Komunikasi Islam Tentang Gender dan Anak, 12 (2), 2016}

b. Represif

Upaya Represif merupakan upaya yang dilakukan pascakekerasan, dengan cara pengobatan dan pemulihan yang diterapkan melalui program Happy Class dan Klinik Psikologi.

4) Happy Class

Program Happy Class merupakan program yang mana anak korban kekerasan dikumpulkan dalam satu kelas bersama korban yang lain untuk mengikuti beberapa kegiatan. Kegiatan ini dilaksanakan yang bertujuan untuk mengobati kesedihan si anak dan membuat si anak lupa terhadap kekerasan yang telah dialaminya.Misalnya dengan mengajak mereka menari, menyanyi, ataupun bermain bersama.

\section{5) Klinik Psikologi}

Klinik Psikologi merupakan program yang mana anak korban kekerasan diberi terapi secara intensif oleh para ahli psikologi.Terapi ini bertujuansupaya korban dapat menghilangkan trauma atas peristiwa yang telah dialami.

\section{Penutup}

Kekerasan terhadap anak merupakan permasalahan yang perlu mendapatkan perhatian khusus. Berbagai data menunjukkan telah terjadi peningkatan kasus kekerasan anak dari tahun ke tahun. Bahkan kekerasan terhadap anak merupakan suatu fenomena gunung es dimana masih sedikit kasus kekerasan anak yang dianggkat ke publik, tetapi dapat dilihat oleh masyarakat banyak sekali.

Rumah Peran SI-PAI merupakan solusi yang tepat ditengah maraknya kasus kekerasan anak di Indonesia yang masih belum terselesaikan. Komisi Perlindungan Anak Indonesia yang diperkenalkan melalui Kepres No. 77 Tahun 2003 Tentang KPAI dan pasal 74 UU No. 23 Tahun 2002 Tentang Perlindungan Anak, secara nyata belum mampu berperan secara optimal dalam menyelesaikan kasus kekerasan anak di Indonesia. Sehingga, solusi berupa Rumah Peran SI-PAI yang berada di bawah KPAI merupakan langkah progresif dan tepat serta mampu dilakukan pemerintah dalam rangka menyelesaikan perrmasalahan kekerasan terhadap anak di Indonesia.

Beberapa rekomendasi yang dapat dikaji dan ditindaklanjuti antara lain adalah: seyogyanya pemerintah fokus menyelesaikan permasalahan tindak kekerasan anak di Indonesia karena persoalan ini telah menjadi sangat penting untuk diselesaikan. Seyogyanya masyarakat mampu berpartisipasi aktif dalam upaya preventif maupun represif terhadap permasalahan tindakan kekerasan di Indonesia.

\section{Keterangan:}

\begin{tabular}{|c|c|c|}
\hline No & Stakeholder & Peran \\
\hline 1. & Komisi Perlindungan Anak Indonesia (KPAI) & $\begin{array}{l}\text { a. Melakukan sosialisasi seluruh ketentuan peraturan perundang- } \\
\text { undangan yang berkaitan dengan perlindungan anak, } \\
\text { mengumpulkan data dan informasi, menerima pengaduan } \\
\text { masyarakat, melakukan penelaahan, pemantauan, evaluasi dan } \\
\text { pengawasan terhadap pelanggaran perlindungan anak; } \\
\text { b. Memberikan laporan, saran, masukan dan pertimbangan kepada } \\
\text { presiden dalam rangka perlindungan anak. } \\
\text { c. Melakukan sosialisasi dan advokasi tentang peraturan perundang- } \\
\text { undangan yang berkaitan dengan perlindungan anak. } \\
\text { d. Menerima pengaduan dan memfasilitasi pelayanan masyarakat } \\
\text { terhadap kasus-kasus pelanggaran hak anak kepada pihak-pihak }\end{array}$ \\
\hline
\end{tabular}




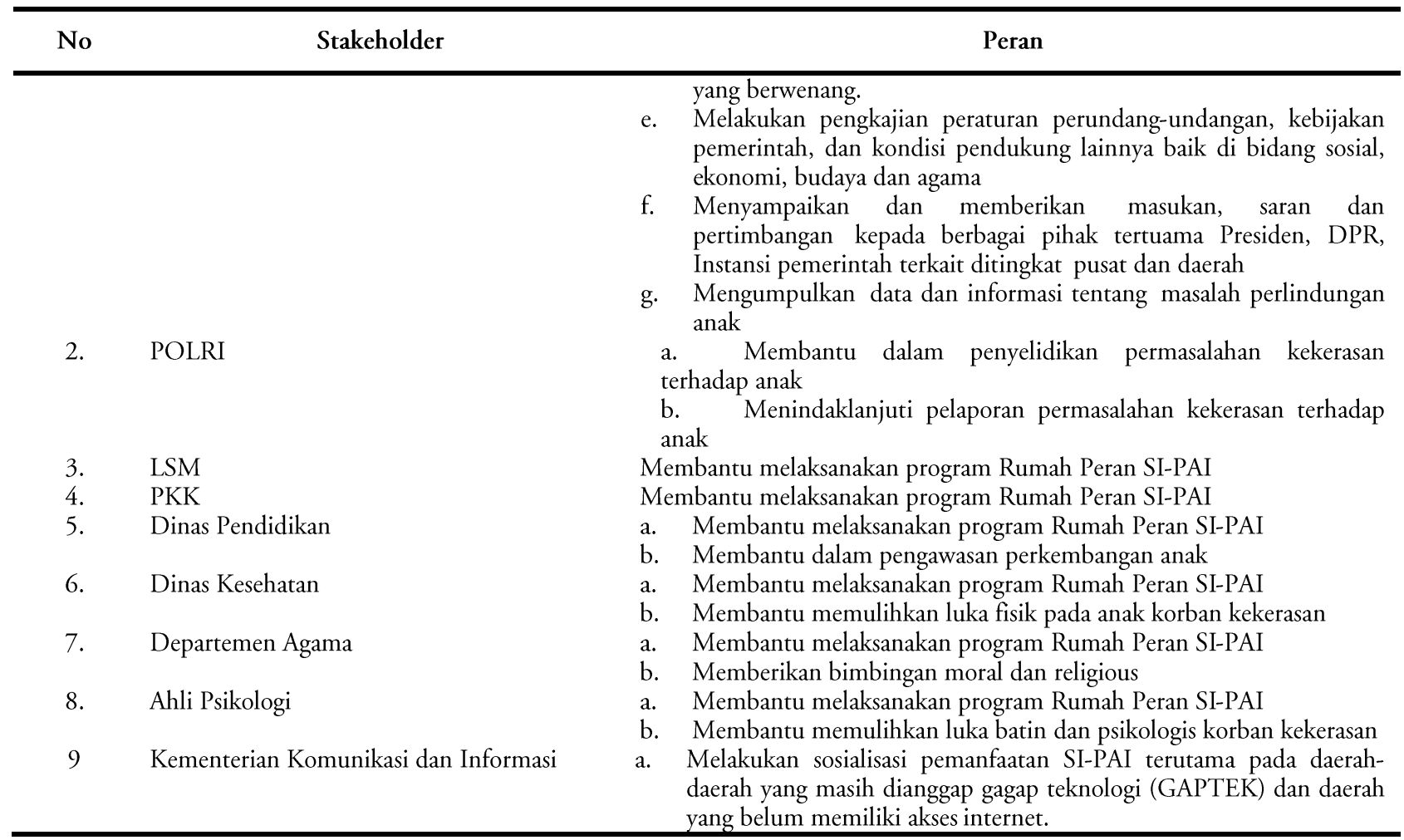

\section{Daftar Pustaka}

Anonim. (http://bps.go.id/), diakses pada tanggal 10 Juli 2016.

Anonim. (http://komnaspa.or.id) diakses tanggal 10 Juli 2016.

Anonim.http://news.liputan6.com/read/2154228 /komnas-pa-prediksi-pelaku-kekerasananak-meningkat-18-tahun-2015, diakses pada tanggal 10 Juli 2016.

Keputusan Presiden Republik Indonesia Nomor 36 Tahun 1990 Tentang Pengesahan Convention on The Rights of the Child (Konvensi Tentang Hak-hak Anak) (Lembaran Negara Republik Indonesia Tahun 1990 Nomor 57).

Konvensi tentang Hak-hak Anak (Convention on the Rights of the Child), Resolusi No. 109 Tahun 1990.
Peraturan Menteri Pemberdayaan Perempuan dan Perlindungan Anak Republik Indonesia Nomor 12 Tahun 2011 Tentang Indikator Kabupaten/Kota Layak Anak.

Sentika, Rachmat. Peran Ilmu Kemanusiaan dalam Meningkatkan Mutu Manusia Indonesia melalui Perlindungan Anak. Jurnal Sosioteknologi Edisi 11 Tahun 6, Agustus 2007.

Undang-undang Dasar Negara Republik Indonesia Tahun 1945.

Undang-undang Republik Indonesia Nomor 23 Tahun 2003 tentang Perlindungan Anak (Lembaran Negara Republik Indonesia Tahun 2002 Nomor 109, Tambahan lembaran Negara Republik Indonesia Nomor 4235). 